\title{
The effect of context attractiveness on product attractiveness and product quality: the moderating role of product familiarity
}

\author{
Benedikt Schnurr ${ }^{1}$ • Alexandra Brunner-Sperdin ${ }^{2}$. \\ Nicola E. Stokburger-Sauer ${ }^{1}$
}

Published online: 9 August 2016

(C) The Author(s) 2016. This article is published with open access at Springerlink.com

\begin{abstract}
Prior research has investigated a number of drivers of consumers' perceived product attractiveness, such as a product's shape and color. The context, in which a product is presented, has so far been largely neglected in examining consumers' aesthetic appraisal of products. Drawing on social cognition theory, this research investigates how the attractiveness of the visual context (e.g., websites, advertisements) influences consumers' perceptions of product attractiveness and product quality for familiar versus unfamiliar products. Results of two experimental studies show that consumers perceive unfamiliar products as more attractive and, consequently, of higher quality when products are placed in an attractive context than when they are placed in an unattractive context. No differences in consumers' perceived product attractiveness and perceived product quality exist for familiar products. The findings extend our theoretical knowledge of product aesthetics and provide managers with insights into the effective communication of their offerings' attractiveness.
\end{abstract}

Keywords Context effects · Product attractiveness · Product quality · Product familiarity

\section{Introduction}

Just as consumers ascribe personality traits, for example social skills and competence, to other people based on their physical attractiveness (Dion et al. 1972; Goldman and Lewis 1977), consumers also make inferences about product attributes based on a product's visual appeal (Bloch 1995; Creusen and Schoormans 2005). While past research provides solid

Benedikt Schnurr

benedikt.schnurr@uibk.ac.at

1 Department of Strategic Management, Marketing, and Tourism, University of Innsbruck, Universitaetsstr. 15, 6020 Innsbruck, Austria

2 Department of Marketing, University of Applied Sciences in Kufstein, Andreas Hofer-Straße 7, 6330 Kufstein, Austria 
knowledge on the design factors that make products more or less attractive (Blijlevens et al. 2011; Veryzer and Hutchinson 1998), it has neglected to examine the influence of the context, in which a product is presented, on consumers' aesthetic appraisal of products. This is surprising considering the fact that products are always perceived in some kind of context, be it a website, an advertisement, a store, or consumers' homes. Consequently, knowing how the context affects consumers' perceptions of products certainly helps companies to display them in a manner that makes them appear most attractive.

The objective of this research is to theoretically and empirically examine context effects in consumers' aesthetic appraisal of products. Specifically, by drawing on social cognition theory (Mussweiler 2003; Schwarz and Bless 1992), we investigate whether consumers perceive products as more or less attractive depending on the attractiveness of the visual context in which the products are presented. Further, we explore whether perceived product attractiveness subsequently affects consumers' perceptions of product quality. In a first experiment, we investigate these context effects using more and less attractive websites. In a second experiment, we validate and extend the results using print advertisements as contexts and, additionally, examine whether higher ratings of product attractiveness translate into higher purchase intentions.

\section{Conceptual background}

\subsection{Context effects and product attractiveness}

Research in cognitive psychology has successfully demonstrated that the context affects consumers' perceptions of target stimuli (Bless and Schwarz 2010; Lee and Suk 2010). Context effects describe processes of consumers' stimulus perceptions that are affected by the environment in which the stimulus is perceived. The concept of cognitive accessibility explains the circumstances under which consumers use contextual information in order to interpret and evaluate a target stimulus. The basic notion of this concept is that the more cognitively accessible information is, the more likely that information is to affect the perception of the target stimulus (Stapel 2007).

The use of information that consumers retrieve from the context in forming an impression about a target stimulus may result in two opposing effects. When the context information is used as a comparison standard, consumers compare the features of the target stimulus with the features of the context and judge the target stimulus in the opposite direction to the context-a contrast effect occurs. When the context information is used as an interpretation frame, it helps to make sense of the target stimulus, and consumers judge the target stimulus in the same direction to the context - an assimilation effect occurs. Whether a contrast effect or an assimilation effect occurs depends on both the characteristics of the context and the target stimulus.

\subsubsection{Contrast effects}

For contrast effects to occur, two conditions need to be met. First, the context and the target stimulus need to belong to the same category (Mussweiler 2003). For example, consumers are likely to compare the elegance of one restaurant with the elegance of another restaurant, while they are unlikely to compare the elegance of a restaurant with 
the elegance of a clothing store (Meyers-Levy and Sternthal 1993). Similarly, when a target product is placed among other products on a website or in an advertisement, consumers are likely to compare the attractiveness of this target product with the attractiveness of the other products but not with the attractiveness of the website or the advertisement. In the latter case, the context and the target stimulus do not belong to the same category, and consumers will not compare the attributes associated with the context against the attributes associated with the target stimulus (Mussweiler 2003).

Second, the context needs to be highly distinct from the target stimulus (Stapel 2007). Only if the attribute that consumers associate with the context is primed in the extreme opposite direction from the attribute that consumers associate with the target stimulus, consumers are likely to use the context as a comparison standard and judge the target stimulus in the opposite direction to the context. When both conditions are met, a positive context leads to a negative evaluation of the target stimulus, while a negative context leads to a positive evaluation of the target stimulus. Investigating facial attractiveness ratings, Wedell et al. (1987) showed that consumers judge the same faces as more attractive when they are presented in a context with less attractive faces.

In the present research, we do not expect contrast effects to occur because the first condition (context and target stimulus belong to the same category) is not satisfied.

\subsubsection{Assimilation effects}

For assimilation effects to occur, the following conditions need to be met. First, the target stimulus needs to be rather ambiguous or unfamiliar (Lee and Suk 2010). In this case, the target stimulus is open to various interpretations, and consumers are likely to transfer the attributes associated with the context to the target stimulus. Second, the type of information that is made accessible through the context has to be relevant for interpreting the target stimulus (Mussweiler 2003; Stapel et al. 1998). Thus, the attributes that consumers associate with the context need to be transferable to the target stimulus. When both conditions are met, a positive context leads to a positive evaluation of the target stimulus, while a negative context leads to a negative evaluation of the target stimulus. In the context of art, Kirk et al. (2009) showed that consumers evaluate paintings labeled as belonging to an art museum more positively than paintings labeled as being computer generated by the experimenter.

Following this reasoning, we expect the occurrence of assimilation effects to be moderated by consumers' product familiarity, which is defined as "the number of product-related experiences that have been accumulated by the consumer" (Alba and Hutchinson 1987, p. 411). Specifically, we propose that assimilation effects occur for unfamiliar products, but not for familiar products. When consumers are highly familiar with a product, they have encountered numerous products and gained experience in appreciating various product appearances. Thus, consumers are able to interpret the attractiveness of a familiar product independently from the context in which the product is presented. However, when consumers encounter a product they are unfamiliar with or have even never seen before, they have no prior experience with the product and, thus, lack the ability to judge the product's attractiveness. Thus, consumers may use the attractiveness of the visual context in forming an impression about the product's attractiveness leading to assimilation effects. Thus, we hypothesize:

H1: When consumers are unfamiliar with the product, they perceive the product as more attractive when the product is placed in an attractive context than when 
the product is placed in an unattractive context. When consumers are familiar with the product, no differences in perceived product attractiveness occur.

\subsection{Product attractiveness and product quality}

Consumers make inferences about numerous product attributes, including functional attributes such as product quality, through a product's visual appearance (Bloch 1995; Creusen and Schoormans 2005). A positive relationship between stimulus attractiveness and product quality has been found in several contexts such as websites (Wang et al. 2011) and retail stores (Richardson et al. 1996). In fact, attractiveness and quality are directly related through the "what is beautiful is good" stereotype (Dion et al. 1972). Researchers have shown that attractive people are more positively evaluated in terms of social skills (Goldman and Lewis 1977) and are believed to be more competent and successful (Dion et al. 1972) compared to less attractive people. Further, in an advertising context, a spill-over effect exists in which physically attractive testimonials used in advertisements lead to more positive perceptions of product quality than physically less attractive testimonials (Petroshius and Crocker 1989).

In this research, we expect that consumers' perceptions of product attractiveness positively influence their perceptions of product quality. When consumers are not provided with any other information about a product and when consumers have no prior experience in using the product, the product's visual appearance serves as an extrinsic cue that facilitates consumers' judgments of product quality (Garber et al. 2000). As suggested above, the attractiveness of the context, in which a product is presented, affects consumers' perceived product attractiveness for unfamiliar products, but not for familiar products. We propose:

$\mathrm{H} 2$ : When consumers are unfamiliar with the product, they perceive the product quality as higher when the product is placed in an attractive context than when the product is placed in an unattractive context. When consumers are familiar with the product, no differences in perceived product quality occur.

H3: The interactive effect of context attractiveness and product familiarity on perceived product quality is mediated by perceived product attractiveness.

\section{Study 1}

\subsection{Method}

\subsubsection{Participants and design}

A total of 194 students from a European university participated voluntarily in study 1 (135 female, $M_{\text {age }}=24.63$ ). Participants were randomly assigned to a 2 (unattractive vs. attractive website) $\times 2$ (unfamiliar vs. familiar product) between-subjects design. 


\subsubsection{Stimuli}

To create the stimuli, two pretests were conducted. In the first pretest, 59 participants ( 31 female, $M_{\text {age }}=23.60$ ) rated their familiarity with 30 products from various categories on the items by Roehm and Sternthal (2001). Results indicated to use a pineapple slicer as the unfamiliar product and a cooking pot as the familiar product $\left(M_{\text {pineapple }}\right.$ slicer $\left.=2.58, M_{\text {cooking pot }}=6.37, p<0.01\right)$.

In the second pretest, 52 participants ( 33 female, $M_{\text {age }}=24.83$ ) were randomly assigned to a 2 (unattractive vs. attractive website) $\times 2$ (unfamiliar vs. familiar product) design. The first factor was manipulated between participants and the latter within participants. We created two screenshots of a fictitious online retailer. Literature shows that attractive websites are high in classical and expressive aesthetics, whereas unattractive websites are low in both aesthetic dimensions (Tractinsky et al. 2006). While classical aesthetics refers to the clarity and order of the web design, expressive aesthetics refers to the richness and creativity of the web design. In line with previous literature (Cai and $\mathrm{Xu} 2011$; Wang et al. 2011), we manipulated the websites' classical aesthetics by varying the logical organization of different website elements as well as the legibility of font type. We manipulated expressive aesthetics by using different text and background color combinations. We did not make any changes in terms of content between the two websites. The participants rated the screenshots on the 9-item classical/expressive web aesthetics scale (Cai and Xu 2011). Further, the participants rated how realistic they found the website ("I can imagine that this website really exists" and "I have seen a website like this before") and the content of the website based on Zhang and von Dran (2001) ("The level of information on this website is appropriate" and "The content of this website is relevant"). Results of a $2 \times 2$ MANOVA showed only significant main effects for website attractiveness, while all main effects for product familiarity as well as all interaction effects were not significant (all $p>0.300$ ). We therefore merged the data across the two different products.

A MANOVA revealed that the attractive websites were perceived higher in terms of both classical aesthetics $\left(M_{\text {attractive }}=4.71, M_{\text {unattractive }}=2.99, p<0.001\right)$ and expressive aesthetics $\left(M_{\text {attractive }}=3.03, M_{\text {unattractive }}=1.20, p<0.001\right)$ than the unattractive website. Further, the two websites did not differ significantly in terms of how realistic they were perceived $\left(M_{\text {unattractive }}=3.92, M_{\text {attractive }}=4.40, p>0.10\right)$ and in terms of website content $\left(M_{\text {unattractive }}=3.92, M_{\text {attractive }}=3.40, p>0.10\right)$. These results show that our manipulation of website attractiveness did not affect participants' perceptions of the websites' realism or content. We, thus, used the two websites (see Fig. 1) as our final stimuli.

\subsubsection{Measurement}

After processing the stimulus, participants indicated their perceptions of product quality on the items provided by Dodds et al. (1991) ("This product seems to be very reliable," "The manufacturing quality of this product seems very high," "The quality of this product is very high," "This product seems to be very dependable," and "This product is likely to be durable"; $\alpha=0.91$ ). Perceived product attractiveness was measured using the items by Page and Herr (2002) ("unattractive/attractive" and "not beautiful/ beautiful"). As a manipulation check, the participants indicated the website's classical $(\alpha=0.78)$ and expressive aesthetics $(\alpha=0.96)$, the degree of realism of the website ("I have seen a website like this before"), as well their familiarity with the product. 


\section{ONLINE SHOP}

\begin{tabular}{llll}
\hline HOME & ARTIKEL & F̈BER UNS & FAQS \\
\hline
\end{tabular}

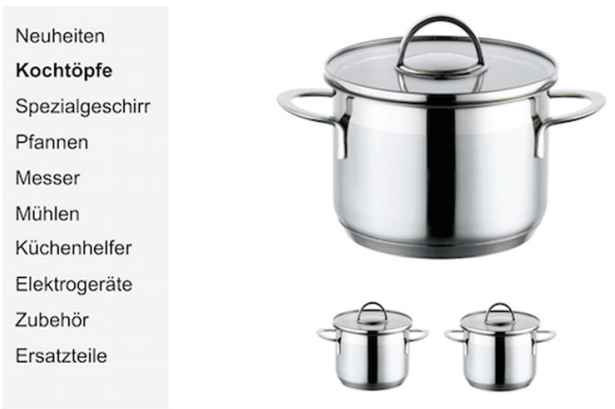

Kochtopf

Produktinformationen noch nicht verfügbar Produktinformationen noch nicht verfügbar Produktinformationen noch nicht verfügbar Produktinformationen noch nicht verfügbar Produktinformationen noch nicht verfügbar

\section{IN DEN EINKAUFSKORB}

Like Tweet Pint

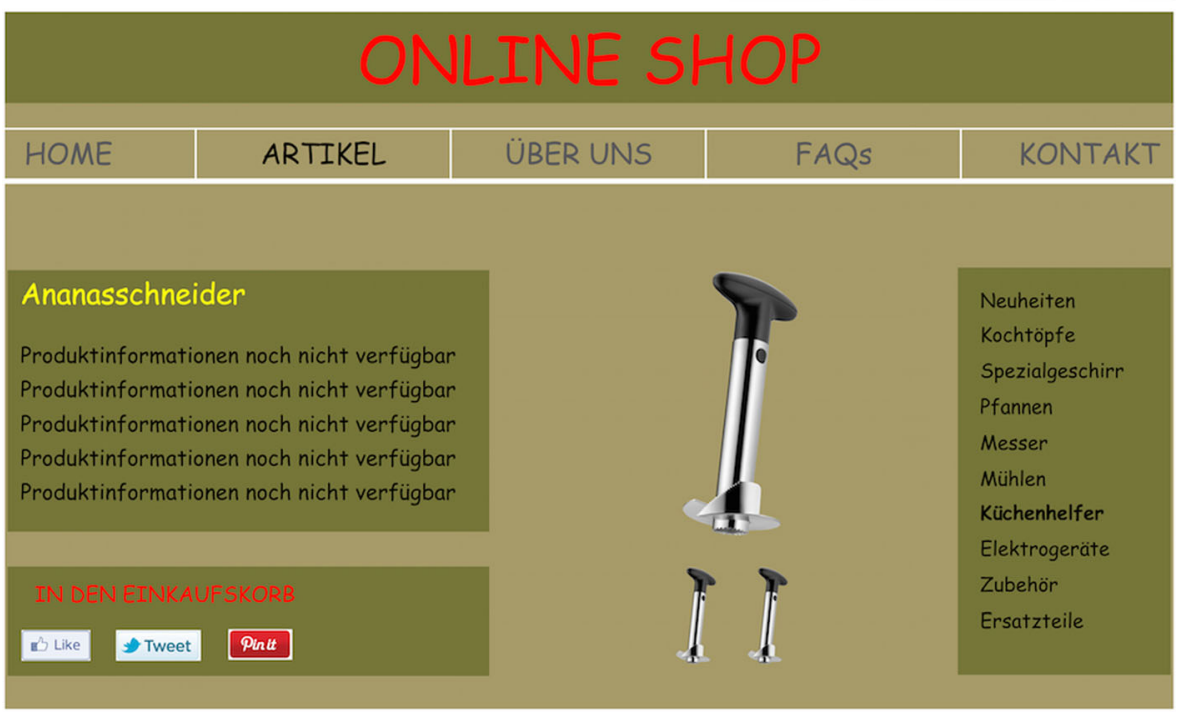

Fig. 1 Familiar product placed on attractive website (top) and unfamiliar product placed on unattractive website (bottom)

\subsection{Results}

\subsubsection{Manipulation check}

The attractive websites were rated higher than the unattractive websites in terms of classical aesthetics $\left(M_{\text {attractive }}=5.49, \mathrm{M}_{\text {unattractive }}=3.59, p<0.001\right)$ and expressive aesthetics $\left(M_{\text {attractive }}=4.49, M_{\text {attractive }}=1.66, p<0.001\right)$. There were no significant differences in the degree of realism between the websites $\left(M_{\text {attractive }}=4.02, M_{\text {unattractive }}=\right.$ $3.54, p>0.10)$. Further, the participants reported higher familiarity with the familiar product than with the unfamiliar product $\left(M_{\text {familiar }}=6.49, M_{\text {unfamiliar }}=2.75, p<0.001\right)$. 


\subsubsection{Perceived product attractiveness}

A $2 \times 2$ ANOVA with website attractiveness and product familiarity as independent variables on perceived product attractiveness revealed a significant main effect for website attractiveness $(F(1,192)=13.67, p<0.001)$ while the effect for product familiarity was not significant $(F(1,192)=0.043, p>0.10)$. The interaction between website attractiveness and product familiarity reached significance $(F(1,192)=6.25, p<0.05)$. As predicted in $\mathrm{H} 1$, the participants perceived the unfamiliar product as more attractive when it was placed on the attractive website than when it was placed on the unattractive website $\left(M_{\text {attractive }}=5.51, M_{\text {unattractive }}=4.55, p<0.001\right)$. No difference was found for the familiar product $\left(M_{\text {attractive }}=5.16, M_{\text {unattractive }}=4.97, p>0.10\right)$.

\subsubsection{Perceived product quality}

A $2 \times 2$ ANOVA on perceived product quality produced a significant main effect for website attractiveness $(F(1,192)=7.26, p<0.01)$. The effect for product familiarity was not significant $(F(1,192)=1.03, p>0.10)$; the interaction reached significance $(F(1,192)=4.25, p<0.05)$. Supporting $\mathrm{H} 2$, the participants rated the quality of the unfamiliar product as higher when the product was placed on the attractive website than when it was placed on the unattractive website $\left(M_{\text {attractive }}=4.47, M_{\text {unattractive }}=3.64\right.$, $p<0.01)$. No difference existed for the familiar product $\left(M_{\text {attractive }}=4.28, M_{\text {unattractive }}=\right.$ $4.17, p>0.10)$.

\subsubsection{Moderated mediation analysis}

To examine whether the interactive effect of website attractiveness and product familiarity on perceived product quality is mediated by perceived product attractiveness, we employed the methodology for testing moderated mediation suggested by Preacher et al. (2007) using the bootstrapping procedure $(n=$ $5000)$. Results indicated the presence of a moderated mediation $\left(\mathrm{CI}_{95} \%=-0.85\right.$, -0.11 ), thus supporting H3. Specifically, perceived product attractiveness mediated the relationship between website attractiveness and perceived product quality for the unfamiliar product $\left(\mathrm{CI}_{95} \%=0.24,0.87\right)$, but not for the familiar product $\left(\mathrm{CI}_{95} \%=-0.11,0.29\right)$.

\subsection{Discussion}

Study 1 demonstrates that the perceptions of product attractiveness of consumers who are unfamiliar with a product are greatly affected by the visual appeal of the context in which the product is presented. Further, this increase in perceptions of product attractiveness leads to an increase in perceptions of product quality. When consumers are familiar with the product, the context does not affect consumers' perceptions of either product attractiveness or product quality.

To validate and extend these findings, we made three critical changes in study 2. First, while websites served as the context in study 1, we chose print 
advertisements in study 2 to show that assimilation effects appear both in an online and offline context. Second, while European students served as the participants in study 1, American consumers were the participants in study 2. Further, in addition to investigating the effects on perceived product quality, we included a measure of purchase intention in study 2 .

\section{Study 2}

\subsection{Product attractiveness and purchase intention}

Consumers' perceptions of product attractiveness influence their behavioral responses towards a product, which are typically described by avoidance or approach (Crilly et al. 2004; Bloch 1995). When a product elicits rather positive perceptions of attractiveness, consumers are likely to engage in approach behavior, such as spending additional time looking at the product or willingness to buy it. In this research, we suggest that consumers' increased perceptions of product attractiveness translate into higher intentions to purchase the product.

H4: When consumers are unfamiliar with the product, their intentions to purchase the product are higher when the product is placed in an attractive context than when the product is placed in an unattractive context. When consumers are familiar with the product, no differences in purchase intentions occur.

H5: The interactive effect of context attractiveness and product familiarity on purchase intention is mediated by perceived product attractiveness.

\subsection{Method}

\subsubsection{Participants and design}

A total of 200 US consumers, recruited via Mechanical Turk, participated in study 2 (84 female, $M_{\text {age }}=35.98$ ). The participants were randomly assigned to a 2 (unattractive vs. attractive ad) $\times 2$ (unfamiliar vs. familiar product) between-subjects design.

\subsubsection{Stimuli}

Similar to study 1 , two pretests were conducted. In the first pretest, 37 participants (15 female, $M_{\text {age }}=34.39$ ) rated their familiarity with 16 products from different product categories. In order to use products from the same product category, we chose the pineapple slicer as the unfamiliar product and the toaster as the familiar product $\left(M_{\text {pineapple slicer }}=2.43, M_{\text {toaster }}=5.96, p<0.01\right)$.

In the second pretest, 189 participants ( 84 female, $\left.M_{\mathrm{age}}=38.75\right)$ were randomly assigned to a 2 (unattractive vs. attractive ad) $\times 2$ (unfamiliar vs. familiar product) between-subjects design. A professional graphic designer created the advertisements by 
varying the degree of classical and expressive aesthetics. The participants rated the advertisements on the 9-item classical/expressive aesthetics scale (Cai and Xu 2011), which was adapted to the advertisement context. Further, the participants rated the content of the advertisement as well as the believability of the advertisement based on the items by Gürhan-Canli and Maheswaran (2000). Results of a $2 \times 2$ MANOVA only revealed significant main effects for ad attractiveness, while all main effects for product familiarity as well as all interaction effects were not significant (all $p>0.200$ ). We therefore merged the data across the two different products.

A MANOVA showed that the attractive advertisements scored higher in terms of both classical aesthetics $\left(M_{\text {attractive }}=4.43, M_{\text {unattractive }}=3.73, p<0.001\right)$ and expressive aesthetics $\left(M_{\text {attractive }}=4.69, M_{\text {unattractive }}=3.16, p<0.001\right)$ than the unattractive advertisements. Further, the advertisements did not differ in terms of content $\left(M_{\text {unattractive }}=\right.$ $\left.4.06, M_{\text {attractive }}=4.14, p>0.10\right)$ and believability $\left(M_{\text {attractive }}=4.95, M_{\text {unattractive }}=4.62\right.$, $p>0.10)$. These results show that our manipulation of advertisement attractiveness did not affect participants' perceptions of content or believability. Further, mean values of above 4.50 for ad believability suggest that our stimuli show acceptable external validity. We, thus, used the two advertisements as our final stimuli (see Fig. 2).

\subsubsection{Measurement}

The same measures as in study 1 were used to assess perceived product quality $(\alpha=0.96)$ and perceived product attractiveness. Additionally, the participants indicated how likely they would purchase the product from 1("very unlikely") to 7("very

\section{TOASTY}

START YOUR DAY WITH THIS NEW TOASTER!
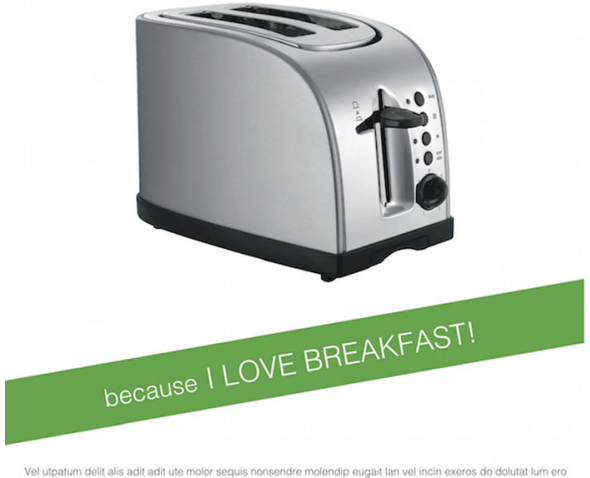

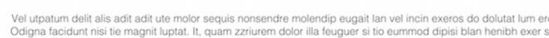

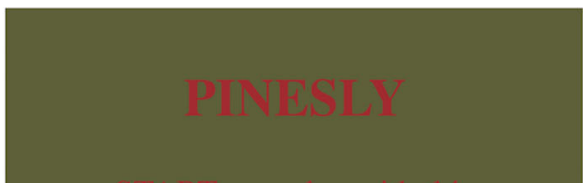

Fig. 2 Attractive advertisement for familiar product (left) and unattractive advertisement for unfamiliar product (right) 
likely"). Finally, the participants assed the advertisement's classical $(\alpha=0.91)$ and expressive aesthetics $(\alpha=0.97)$, the degree of realism of the ad, as well as their familiarity with the product on the same items used in study 1 .

\subsection{Results}

\subsubsection{Manipulation check}

The attractive advertisements were rated higher than the unattractive advertisements in terms of classical aesthetics $\left(M_{\text {attractive }}=4.94, M_{\text {unattractive }}=4.01, p<0.001\right)$ and expressive aesthetics $\left(M_{\text {attractive }}=4.81, M_{\text {unattractive }}=3.39, p<0.001\right)$. Also, there were no differences in the degree of realism between the advertisements $\left(M_{\text {attractive }}=2.71, M_{\text {unattractive }}=2.34\right.$, $p>0.10)$. Further, the participants reported higher familiarity with the familiar product than with the unfamiliar product $\left(M_{\text {familiar }}=5.62, M_{\text {unfamiliar }}=2.39, p<0.001\right)$.

\subsubsection{Perceived product attractiveness}

A $2 \times 2$ ANOVA with advertisement attractiveness and product familiarity as independent variables on perceived product attractiveness revealed a non-significant main effect for product familiarity $(F(1,198)=0.428, p>0.10)$ and a significant main effect for ad attractiveness $(F(1,198)=7.98, p<0.01)$. The interaction between ad attractiveness and product familiarity reached significance $(F(1,198)=12.57, p<0.001)$. Congruent with $\mathrm{H} 1$, the participants perceived the unfamiliar product as more attractive when it was shown in the attractive advertisement than when it was shown in the unattractive advertisement $\left(M_{\text {attractive }}=5.65, M_{\text {unattractive }}=4.54, p<0.001\right)$. No difference was found for the familiar product $\left(M_{\text {attractive }}=5.15, M_{\text {unattractive }}=5.27, p>0.10\right)$.

\subsubsection{Perceived product quality}

A $2 \times 2$ ANOVA on perceived product quality revealed significant main effects for product familiarity $(F(1,1981)=2.93, p<0.10)$ and ad attractiveness $(F(1,198)=5.71$, $p<0.05)$. Further, the interaction was significant $(F(1,198)=3.98, p<0.05)$. In support of $\mathrm{H} 2$, the participants rated the quality of the unfamiliar product higher when the product was shown in the attractive advertisement than when it was shown in the unattractive advertisement $\left(M_{\text {attractive }}=5.61, M_{\text {unattractive }}=5.03, p<0.01\right)$. No difference existed for the familiar product $\left(M_{\text {attractive }}=5.12, M_{\text {unattractive }}=5.07, p>0.10\right)$.

\subsubsection{Purchase intention}

A $2 \times 2$ ANOVA on purchase intention produced a significant main effect for product familiarity $(F(1,198)=4.89, p<0.05)$ while the effect for ad attractiveness did not reach significance $(F(1,198)=1.41, p>0.10)$. The interaction turned out to be significant $(F(1,198)=6.21, p<0.05)$. Supporting H4, the participants indicated a higher purchase intention for the unfamiliar product when the product was shown in the attractive advertisement than when it was shown in the unattractive advertisement $\left(M_{\text {attractive }}=4.59, M_{\text {unattractive }}=3.67, p<0.05\right)$. No effect was found for the familiar product $\left(M_{\text {attractive }}=4.52, M_{\text {unattractive }}=4.84, p>0.10\right)$. 


\subsubsection{Moderated mediation analyses}

To test for the existence of a moderated mediation, we applied the same procedure as in study 1 . Including perceived product quality as the dependent variable, results indicated the presence of a moderated mediation $\left(\mathrm{CI}_{95} \%=-0.82,-0.22\right)$, supporting $\mathrm{H} 3$. Specifically, perceived product attractiveness mediated the relationship between ad attractiveness and perceived product quality for the unfamiliar product $\left(\mathrm{CI}_{95} \%=0.25,0.68\right)$, but not for the familiar product $\left(\mathrm{CI}_{95} \%=-0.27,0.15\right)$.

To test H5, we included purchase intention as the dependent variable. Results revealed the presence of a moderated mediation $\left(\mathrm{CI}_{95} \%=-1.662,-0.48\right)$. Perceived product attractiveness mediated the relationship between ad attractiveness and purchase intention for the unfamiliar product $\left(\mathrm{CI}_{95} \%=0.55,1.14\right)$, but not for the familiar product $\left(\mathrm{CI}_{95} \%=-0.53,0.31\right)$.

\section{General discussion}

In the two studies with different contexts and different consumers, we showed that the consumers who are unfamiliar with a product perceive the product as more attractive and, consequently, of higher quality when the product is placed in an attractive context than when it is placed in an unattractive context. Further, the higher ratings of product attractiveness translate into higher intentions to purchase the product. When the consumers are familiar with the product, no differences between the attractive and unattractive context exist.

Our findings make important contributions to the literature. First, we provide evidence for the existence of assimilation effects in consumers' aesthetic appraisal of products. While previous studies have mainly focused on the relationship between product form and consumers' aesthetic appraisal, our results suggest that when the consumers are unfamiliar with a product, they take the attractiveness of the context, in which the product is presented, into account when judging the product's attractiveness. Second, we contribute to Bloch's (1995) theoretical propositions by empirically showing that consumers' responses to a product's visual appearance are influenced by the context in which the product is perceived. Third, our results provide empirical proof for the "what is beautiful is good" stereotype (Dion et al. 1972) in a consumer product context. In both the experiments, perceived product attractiveness had a positive effect on perceived product quality.

From a managerial perspective, our findings assist marketers to more effectively position their products and to communicate their products' visual appeal. Specifically, we show that a visually appealing context is more important when consumers are unfamiliar, rather than familiar, with products. When the consumers are unfamiliar with products, they perceive products more attractive when the products are placed in a visually appealing context. This situation may occur when radically new products are launched, when companies seek to target new customer segments, when buying a gift for someone else, or when parents want to buy something for their children. In these situations, it is critical for marketers to present their offerings in a context that is as visually appealing as possible, be it a website, an advertisement, or a department store. For example, when companies launch new products, which are unfamiliar to 
consumers, these companies may profit from using advertisements with superior aesthetic appeal. Likewise, such companies could use an aesthetically appealing context in order to compensate for a possible lack of experience and expertise in producing products with a superior visual design.

Despite these advances, our research has limitations that suggest directions for future research. First, we limited our research to the investigation of assimilation effects in consumers' aesthetic appraisal of products. A recent study by Blijlevens et al. (2012) provides evidence that consumers perceive typical products as more typical when presented in an atypical context than when presented in a typical context. It would be interesting to investigate whether consumers judge an attractive product as more attractive when the product is placed among unattractive products than when it is placed among attractive products. Second, we limited the context to websites and advertisements. Researchers should investigate the effects with products placed in other contexts, for example retail stores. Third, it is likely that personality characteristics moderate the existence of assimilation effects. For example, consumers with a high centrality of visual product aesthetics (CVPA; Bloch et al. 2003) might be less influenced by the attractiveness of the context compared to those with a low CVPA. Likewise, the effect might be moderated by the product category, such that it is stronger for hedonic products for which aesthetics is of great importance to consumers (e.g., clothing, furniture), compared to utilitarian products for which aesthetics is only of minor importance (e.g., tooth paste, batteries).

Acknowledgements Open access funding provided by University of Innsbruck and Medical University of Innsbruck.

Open Access This article is distributed under the terms of the Creative Commons Attribution 4.0 International License (http://creativecommons.org/licenses/by/4.0/), which permits unrestricted use, distribution, and reproduction in any medium, provided you give appropriate credit to the original author(s) and the source, provide a link to the Creative Commons license, and indicate if changes were made.

\section{References}

Alba, J. W., \& Hutchinson, J. W. (1987). Dimensions of consumer expertise. Journal of Consumer Research, 13(4), 411-454.

Bless, H., \& Schwarz, N. (2010). Mental construal and the emergence of assimilation and contrast effects: the inclusion/exclusion model. Advances in Experimental Social Psychology, 42, 319-373.

Blijlevens, J., Carbon, C.-C., Mugge, R., \& Schoormans, J. P. L. (2011). Aesthetic appraisal of product designs: independent effects of typicality and arousal. British Journal of Psychology, 103(1), 44-57.

Blijlevens, J., Gemser, G., \& Mugge, R. (2012). The importance of being "well-placed": the influence of context on perceived typicality and esthetic appraisal of product appearance. Acta Psychologica, 139(1), 178-186.

Bloch, P. H. (1995). Seeking the ideal form: product design and consumer response. Journal of Marketing, 59(3), 16-29.

Bloch, P. H., Brunel, F. F., Arnold, T. J. (2003). Individual differences in the centrality of visual product aesthetics: concept and measurement. Journal of Consumer Research, 29(4), 551-565.

Cai, S., \& Xu, Y. (2011). Designing not just for pleasure: effects of web site aesthetics on consumer shopping value. International Journal of Electronic Commerce, 15(4), 159-188.

Creusen, M. E. H., \& Schoormans, J. P. L. (2005). The different roles of product appearance in consumer choice. Journal of Product Innovation Management, 22(1), 63-81. 
Crilly, N., Moultrie, J., \& Clarkson, P. J. (2004). Seeing things: consumer response to the visual domain in product design. Design Studies, 25(6), 547-577.

Dion, K., Berscheid, E., \& Walster, E. (1972). What is beautiful is good. Journal of Personality and Social Psychology, 24(3), 285-290.

Dodds, W. B., Monroe, K. B., \& Grewal, D. (1991). Effects of price, brand, and store information on buyers' product evaluations. Journal of Marketing Research, 28(3), 307-319.

Garber, L. L., Hyatt, E. M., \& Starr, R. G. (2000). The effects of food color on perceived flavor. Journal of Marketing Theory and Practice, 8(4), 59-72.

Goldman, W., \& Lewis, P. (1977). Beautiful is good: evidence that the physically attractive are more socially skillful. Journal of Experimental Social Psychology, 13(2), 125-130.

Gürhan-Canli, Z., \& Maheswaran, D. (2000). Determinants of country-of-origin evaluations. Journal of Consumer Research, 27(1), 96-108.

Kirk, U., Skov, M., Hulme, O., Christensen, M. S., \& Zeki, S. (2009). Modulation of aesthetic value by semantic context: an fMRI study. NeuroImage, 44(3), 1125-1132.

Lee, M. P., \& Suk, K. (2010). Disambiguating the role of ambiguity in perceptual assimilation and contrast effects. Journal of Consumer Research, 36(5), 890-897.

Meyers-Levy, J., \& Sternthal, B. (1993). A two-factor explanation of assimilation and contrast effects. Journal of Marketing Research, 30(3), 359-368.

Mussweiler, T. (2003). Comparison processes in social judgment: mechanisms and consequences. Psychological Review, 110(3), 472-489.

Page, C., \& Herr, P. M. (2002). An investigation of the processes by which product design and brand strength interact to determine initial affect and quality judgments. Journal of Consumer Psychology, 12(2), 133147.

Petroshius, S. M., \& Crocker, K. E. (1989). An empirical analysis of spokesperson characteristics on advertisement and product evaluations. Journal of the Academy of Marketing Science, 17(3), 217-225.

Preacher, K. J., Rucker, D. D., \& Hayes, A. F. (2007). Addressing moderated mediation hypotheses: theory, methods, and prescriptions. Multivariate Behavioral Research, 42(1), 185-227.

Richardson, P., Jain, A. K., \& Dick, A. (1996). The influence of store aesthetics on evaluation of private label brands. Journal of Product \& Brand Management, 5(1), 19-28.

Roehm, M. L., \& Sternthal, B. (2001). The moderating effect of knowledge and resources on the persuasive impact of analogies. Journal of Consumer Research, 28(2), 257-272.

Schwarz, N., \& Bless, H. (1992). Constructing reality and its alternatives: an inclusion/exclusion model of assimilation and contrast effects in social judgment. In M. L. Leonard \& A. Tessa (Eds.), The construction of social judgments. Hillsdale: Lawrence Erlbaum Associates, Inc.

Stapel, D. A. (2007). In the mind of the beholder: the interpretation comparison model of accessibility effects. In D. A. Stapel \& J. Suls (Eds.), Assimilation and contrast in social psychology. New York: Psychology Press.

Stapel, D. A., Koomen, W., \& Velthuijsen, A. S. (1998). Assimilation or contrast?: comparison relevance, distinctness, and the impact of accessible information on consumer judgments. Journal of Consumer Psychology, 7(1), 1-24.

Tractinsky, N., Cokhavi, A., Kirschenbaum, M., \& Sharfi, T. (2006). Evaluating the consistency of immediate aesthetic perceptions of web pages. International Journal of Human-Computer Studies, 64(11), 10711083.

Veryzer, R. W., \& Hutchinson, J. W. (1998). The influence of unity and prototypicality on aesthetic responses to new product designs. Journal of Consumer Research, 24(4), 374-394.

Wang, Y. J., Minor, M. S., \& Wei, J. (2011). Aesthetics and the online shopping environment: understanding consumer responses. Journal of Retailing, 87(1), 46-58.

Wedell, D. H., Parducci, A., \& Geiselman, R. E. (1987). A formal analysis of ratings of physical attractiveness: successive contrast and simultaneous assimilation. Journal of Experimental Social Psychology, 23(3), 230-249.

Zhang, P., \& von Dran, G. M. (2001). User expectations and rankings of quality factors in different web site domains. International Journal of Electronic Commerce, 6(2), 9-33. 